\title{
Lithium and electrical properties of $\mathrm{ZnO}$
}

\author{
L. Vines ${ }^{1}{ }^{*}$ E.V. Monakhov ${ }^{1}$, R. Schifano ${ }^{1}$, W. Mtangi ${ }^{2}$, F. D. Auret ${ }^{2}$, and B.G. Svensson ${ }^{1}$ \\ 1 University of Oslo, Department of Physics/Centre \\ for Materials Science and Nanotechnology, \\ P.O. Box 1048 Blindern, N-0316 Oslo, Norway and \\ 2 University of Pretoria, Department of Physics, ZA-0002 Pretoria, South Africa
}

(Dated: March 25, 2010)

\begin{abstract}
Hydrothermally grown n-type $\mathrm{ZnO}$ samples have been investigated by deep level transient spectroscopy (DLTS), thermal admittance spectroscopy (TAS), temperature dependent Hall effect (TDH) measurements, and secondary ion mass spectrometry (SIMS) after thermal treatments up to $1500^{\circ} \mathrm{C}$, in order to study the electrical properties of samples with different lithium content. The SIMS results showed that the most pronounced impurities were $\mathrm{Li}, \mathrm{Al}, \mathrm{Si}, \mathrm{Mg}, \mathrm{Ni}$ and $\mathrm{Fe}$ with concentrations up to $\sim 5 \times 10^{17} \mathrm{~cm}^{-3}$. The Li concentration was reduced from $\sim 10^{17} \mathrm{~cm}^{-3}$ in as-grown samples to $\sim 10^{15} \mathrm{~cm}^{-3}$ for samples treated at $1500^{\circ} \mathrm{C}$, while the concentration of all the other major impurities appeared stable. The results from DLTS and TAS displayed at least five different levels having energy positions of $E_{c}-20 \mathrm{meV}, E_{c}-55 \mathrm{meV}, E_{c}-0.22 \mathrm{eV}$, $E_{c}-0.30 \mathrm{eV}$, and $E_{c}-0.57 \mathrm{eV}$ ( $E_{c}$ denotes the conduction band edge), where the $E_{c}-55 \mathrm{meV}$ level is the dominant freeze out level for conduction electrons in samples treated at temperatures $<1300^{\circ} \mathrm{C}$, while higher annealing temperatures revealed the shallower $\left(E_{c}-20 \mathrm{meV}\right)$ level. The TDH measurements showed a pronounced increase in the electron mobility for the heat treated samples, where a peak mobility of $1180 \mathrm{~cm}^{2} / V s$ was reached for a sample treated at $1300^{\circ} \mathrm{C}$. The results provide strong evidence that $\mathrm{Li}$ in hydrothermal $\mathrm{ZnO}$ is almost exclusively in the substitutional configuration $\left(L i_{Z n}\right)$, supporting theoretical predictions that the formation of $L i_{Z n}$ prevails over $\mathrm{Li}$ on the interstitial site for Fermi level positions at and above the middle of the band gap.
\end{abstract}

PACS numbers:

*Electronic address: Lasse.Vines@fys.uio.no 


\section{INTRODUCTION}

Zinc oxide $(\mathrm{ZnO})$ is a wide band gap semiconductor $\left(E_{g} \simeq 3.4 \mathrm{eV}\right)$ that has received considerable attention during the last few years due to its potential applications for light emitting devices and photovoltaics. However, the technological advances of $\mathrm{ZnO}$ have been hindered by the difficulty in controlling and understanding the electrial behavior of intrinsic and impurity related defects. Lithium is one of the most important impurities from both a scientific and a technological point of view; indeed, hydrothermally grown $\mathrm{ZnO}$ normally contains considerable amount of $\operatorname{Li}\left(\gtrsim 10^{17} \mathrm{~cm}^{-3}\right)$, and it has been proposed that Li can act both as a donor and an acceptor, depending on the atomic configuration. Theory suggests that $\mathrm{Li}$ on a zinc site $\left(L i_{Z n}\right)$ is a shallow acceptor, while $\mathrm{Li}$ on an interstitial site $\left(L i_{I}\right)$ is a donor [1] [2], and this is supported by, e.g., electron paramagnetic resonance (EPR) data [3] [4]. The presence of Li can, therefore, result in self-compensation and increase of the resistivity, which is often observed in hydrothermally grown $\mathrm{ZnO}$ [5]. It should also be mentioned that $\mathrm{Li}$ is considered to be involved in a deep band gap state [6], but this state may arise from a complex defect with Li as only one of several constituents [2].

So far, temperature dependent Hall effect (TDH) measurements have played an important role to obtain information about electrically active defect centers in $\mathrm{ZnO}$. However, deep level transient spectroscopy (DLTS) and thermal admittance spectroscopy (TAS) can give more quantitative and direct information about defect concentrations, energy level positions, and charge carrier capture cross sections. Only a few studies using DLTS and TAS for ZnO have been reported, presumably due to the difficulty in producing high quality Schottky barrier contacts. However, recent progress, see e.g. refs. [7][8], shows promising results for Schottky contacts of sufficient quality to pursue DLTS studies of ZnO. Several prominent defect levels are revealed, where a level around $E_{c}-0.3 \mathrm{eV}$ ( $E_{c}$ denotes the conduction band edge) is commonly reported [7] [9] and found irrespective of the growth technique used. This level has been attributed to oxygen vacancies [10], but impurities like $\mathrm{Fe}$ and $\mathrm{Ni}$, and the second ionization level of $Z n_{i}$ have also been proposed [11] [12]. In addition, TAS and TDH reveal several pronounced levels close to $E_{c}$, having activation energies of $\sim 30 \mathrm{meV}$ and $\sim 50-70 \mathrm{meV}$ [13] [14] [15]. Despite these efforts, the band gap states of Li have not been identified by neither DLTS nor TAS, and the existence of the theoretically predicted shallow donor state of $L i_{I}$ has not been confirmed experimentally. For the acceptor state of $L i_{Z n}$, 
a tentative assignment to a level with an activation energy of $\sim 0.25 \mathrm{eV}$ has been made based on results from thermally stimulated current spectroscopy and cathodoluminescence spectroscopy measurements [16] [17] [18].

In this work, we report on impurity concentrations and electrically active defect centers in hydrothermally grown ZnO using TDH, DLTS, TAS, and secondary ion mass spectrometry (SIMS). In particular, the role of $\mathrm{Li}$ is investigated in detail employing samples heat treated up to $1500^{\circ} \mathrm{C}$, yielding a decrease in the Li concentration by almost three orders of magnitude, and the results provide evidence that $L i_{Z n}$ prevails strongly in n-type samples, preventing detection of the donor state ascribed to $L i_{I}$.

\section{EXPERIMENTAL}

Hydrothermally grown $\mathrm{ZnO}$ wafers purchased from SPC Goodwill have been cut in $5 \times$ $5 \mathrm{~mm}$ samples. The resistivity at room temperature (RT) of the as-grown wafers was above $1 k \Omega c m$ for all the wafers except one, which had a resistivity of $\sim 120 \Omega c m$ (Sample 1), as deduced from four-point probe measurements. The samples, labelled 1 to 10, were subjected to heat treatments in ambient air at temperatures up to $1500^{\circ} \mathrm{C}$, see Table I. After heat treatment at and above $1250^{\circ} \mathrm{C}$ the surface roughness of the samples increased considerably $(\mathrm{rms} \sim 3 \mu \mathrm{m})$ and the samples were then mechanically polished using a diamond suspension with grain sizes from $15 \mu \mathrm{m}$ down to $0.25 \mu \mathrm{m}$, reducing the surface roughness to $\sim 10 \mathrm{~nm}$ [19]. For all the measurements, the O-face (0001) was used as front surface.

TDH measurements were carried out on the samples 2,5,7 and 10. Using a Van Der Pauw configuration, an In drop was soldered as Ohmic contact in the corners of the samples. The TDH scans were performed in the temperature range $35-330 \mathrm{~K}$ with a probing magnetic field strength of $0.6 \mathrm{~T}$. All the measurements were undertaken with the samples in vacuum and no exposure to light.

For TAS and DLTS characterization, the samples were subjected to a pretreatment for 5 min in acetone, ethanol and hydrogenperoxide before $100 \mathrm{~nm}$ thick $\mathrm{Pd}$ contacts with diameters between 0.275 and $0.78 \mathrm{~mm}$ were deposited using e-beam evaporation. A post-deposition treatment of the contacts at $200^{\circ} \mathrm{C}$ for 30 min was employed, resulting in a rectification of the current by 2-4 orders of magnitude between forward and reverse bias, as observed by current-voltage (IV) measurements. No rectifying behavior was observed for sample 2 due 
to the high resistivity, and this sample was not subjected to TAS and DLTS characterization. In fact, except for sample no. 1 a post-growth treatment at temperatures $\geq 100^{\circ} \mathrm{C}$ was found necessary in order to obtain reliable Schottky barrier contacts. The DLTS and TAS measurements were performed using a setup described in detail elsewhere [20] [15], and results for the net carrier concentration, deduced from capacitance-voltage (CV) measurements performed at RT with probe frequency of $1 \mathrm{MHz}$, are depicted in Table I. The data exhibit an increasing trend with annealing temperature, in accordance with that reported in Ref. [21].

The chemical characterization was carried out by SIMS using a Cameca IMS $7 \mathrm{f}$ instrument with a primary beam of $10 \mathrm{keV} \mathrm{O}_{2}^{+}$or $15 \mathrm{keV} \mathrm{Cs}^{+}$ions. Concentration versus depth profiles were recorded to a depth of about $3 \mu \mathrm{m}$, where stable SIMS intensities were obtained. Calibration of the SIMS signals were performed using ion-implanted reference samples of Li, $\mathrm{Al}, \mathrm{Mg}, \mathrm{H}, \mathrm{Si}$, and $\mathrm{C}$, while the concentration of $\mathrm{Fe}$ and $\mathrm{Ni}$ was estimated using relative sensitivity factors. The depth of the sputtered craters was measured with a Dektak 8 stylus profilometer and a constant erosion rate for depth calibration was assumed.

During heat treatment above $1000^{\circ} \mathrm{C}$, a build-up of $\mathrm{Li}$ in the near surface region occurs [21] [19] [8] and the accumulation increases with temperature, concurrent with the increase in surface roughness. However, the mechanical polishing, discussed previously and undertaken on samples annealed at and above $1250^{\circ} \mathrm{C}$, does not only improve the surface smoothness but removes also the layer with accumulated Li. More than $50 \mu \mathrm{m}$ of the samples thickness was removed by polishing the O-face, which is sufficient to record constant concentration versus depth profiles during subsequent SIMS analysis [8]. Hence, the impurity concentrations determined by SIMS and discussed in section III represent true bulk values.

\section{RESULTS}

Figure 1 shows typical TAS spectra for four different measurement frequencies. For a measurement frequency of $1 \mathrm{MHz}$ the capacitance, Fig. 1(b), displays a slow decrease when cooling down from room temperature to $\sim 130 K$. Then carrier freeze-out starts to occur with a characteristic temperature $t_{\text {set }}$ equal to $105 \mathrm{~K}$, which corresponds to the position of half of the amplitude of the capacitance step. Concurrently, $G(\omega) / \omega$ reaches a maximum at $t_{\text {set }}$, Fig. 1(a), and the energy position of the freeze out level was found to be $55 \mathrm{meV}$ below 
TABLE I: Sample overview

\begin{tabular}{|l|l|l|}
\hline Sample & $\begin{array}{l}\text { Heat treatment } \\
\text { OC }(1 \text { hour })\end{array}$ & $\begin{array}{l}\text { Carrier concentration at RT } \\
\left(\mathrm{cm}^{-3}\right)(\text { from CV })\end{array}$ \\
\hline 1 & & $\begin{array}{l}2.8 \times 10^{16} \\
\mathrm{NA}\end{array}$ \\
2 & 1100 & $1.1 \times 10^{17}$ \\
3 & 1250 & $3.1 \times 10^{17}$ \\
4 & 1300 & $1.3 \times 10^{17}$ \\
5 & 1400 & $1.5 \times 10^{17}$ \\
6 & 1400 & $1.2 \times 10^{17}$ \\
7 & 1500 & $4.6 \times 10^{17}$ \\
8 & 1500 & $2.4 \times 10^{17}$ \\
9 & 1500 & \\
\hline
\end{tabular}
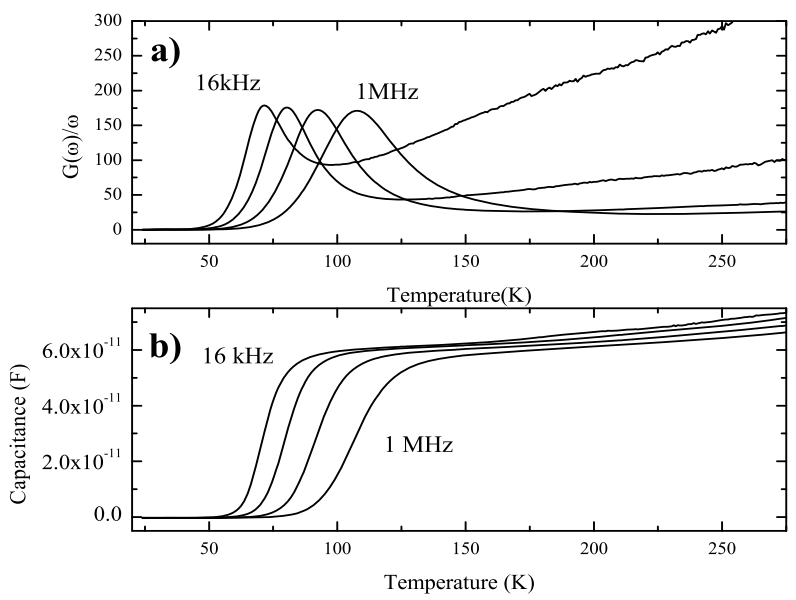

FIG. 1: Capacitance (a) and conductance normalized by the probing angular frequency (b) versus temperature obtained for Pd Schottky diodes on $\mathrm{n}-\mathrm{ZnO}$, sample 4. The measurement frequencies shown are $16 \mathrm{kHz}, 60 \mathrm{kHz}, 250 \mathrm{kHz}$, and $1 \mathrm{MHz}$, respectively. The bias voltage was set to $-1 \mathrm{~V}$ and the probing voltage was $30 \mathrm{mV}$.

$E_{c}$.

Figure 2 shows the capacitance versus temperature for different samples using a probe frequency of $1 \mathrm{MHz}$. One can observe a shift in $t_{\text {set }}$ from $\sim 105 \mathrm{~K}$ to $\sim 25 \mathrm{~K}$ after heat treatments above $1250^{\circ} \mathrm{C}$. The freeze-out at $25 \mathrm{~K}$ corresponds to a level position at $E_{c}-$ 


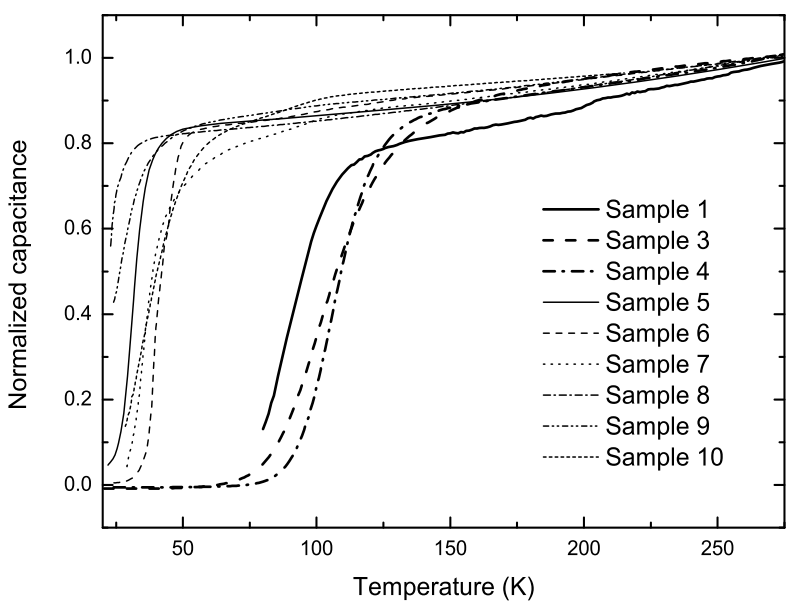

FIG. 2: Normalized capacitance versus temperature obtained for all the diodes using a measurement frequency of $1 \mathrm{MHz}$. The normalization is performed in order to facilitate comparison between diodes with different area size and measurements with different reverse bias voltage used.

$20 \mathrm{meV}$. The shift is consistent between the samples, that is, no admittance signature from the $\sim 20 \mathrm{meV}$ level is observed in any sample heat treated at temperatures $\leq 1250^{\circ} \mathrm{C}$, while the $\sim 55 \mathrm{meV}$ level is not observed in any sample treated at and above $1300^{\circ} \mathrm{C}$.

It should also be noted that the charge carrier concentration exhibits an increasing trend with increasing annealing temperature, see Table I and Refs. [21] [19]. Since the reverse bias was kept constant $(\simeq-1 V)$ for all the samples during the measurements, the probing region varies somewhat for the samples, i.e. the probing region for the samples treated at high temperatures is closer to the surface compared to that for the samples treated at lower temperatures.

The $E_{c}-0.3 \mathrm{eV}$ level commonly reported in $\mathrm{ZnO}$ samples [22] [13] [7] is difficult to observe in the TAS spectra (Fig. 2) since the Fermi level position, $E_{F}$, remains close to $E_{c}$ and no crossing of the $E_{c}-0.3 \mathrm{eV}$ level occurs in the bulk of the samples. However, the level is clearly seen in the DLTS spectra (Fig. 3); its concentration varies from $1.5 \times 10^{15}$ to $1 \times 10^{16} \mathrm{~cm}^{-3}$ with an increase for annealing temperatures up to $1250^{\circ} \mathrm{C}$ and then a decrease at higher temperatures. In addition, two other levels are observed in Fig. 3, labeled E4 and E5, and their positions are found to be $E_{c}-0.22 \mathrm{eV}$ and $E_{c}-0.57 \mathrm{eV}$, respectively. Both levels have previously been reported [7] [23], where the latter was tentatively associated with the oxygen vacancy. The apparent capture cross sections for E3, E4 and E5 are $1.6 \times 10^{-15}$, $5.0 \times 10^{-13}$, and $1.5 \times 10^{-16} \mathrm{~cm}^{2}$, respectively. 


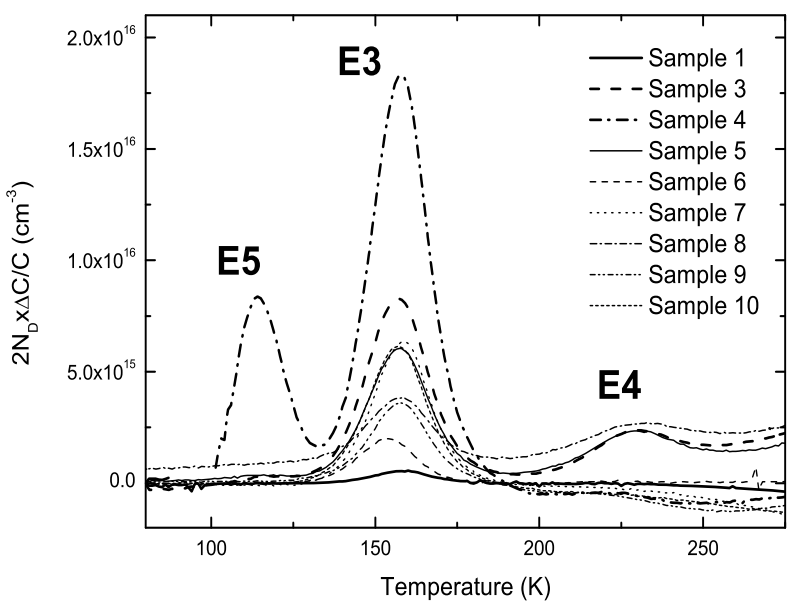

FIG. 3: DLTS spectra of $\mathrm{ZnO}$ samples treated at different temperatures ( rate window $=$ $\left.(640 \mathrm{~ms})^{-1}\right) . \quad N_{D}$ is the charge carrier concentration, $\Delta C$ is the change in capacitance, and $C$ is the quiescent reverse bias capacitance.

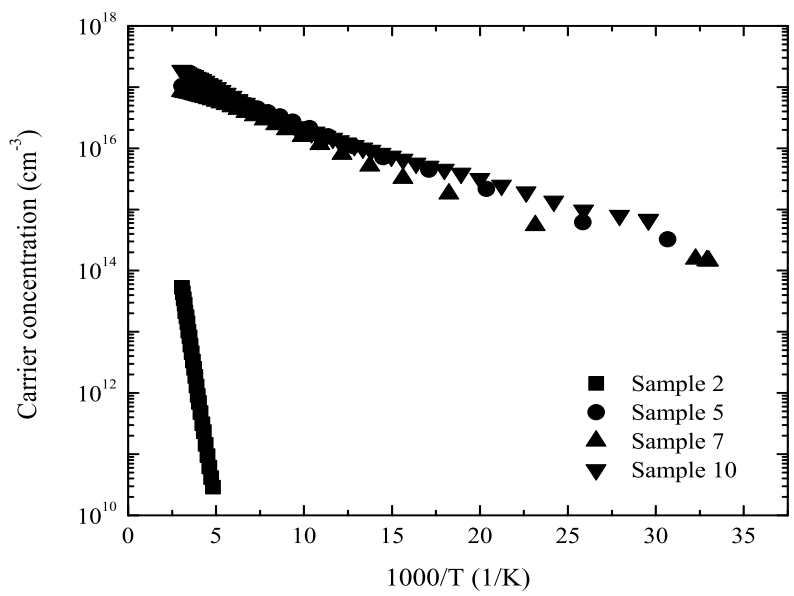

FIG. 4: Carrier concentration from Hall measurements as a function of the reciprocal temperature.

Figures 4 and 5 show the carrier concentration versus the reciprocal absolute temperature and the Hall mobility as a function of temperature, respectively, for samples 2,5,7, and 10. The as-grown sample (no. 2) has a low carrier concentration $\left(<10^{14} \mathrm{~cm}^{-3}\right.$ at RT), while all the heat treated ones exhibit at least three orders of magnitude higher values $\left(\sim 10^{17} \mathrm{~cm}^{-3}\right.$ at RT). Likewise, the mobility is low for the as-grown sample, while a pronounced increase is observed for the heat treated ones, with a peak mobility up to $1180 \mathrm{~cm}^{2} / \mathrm{Vs}$. If these results are combined with those reported by Schifano et al. [14], unambiguous evidence is obtained for a large reduction in ionized impurity/defect scattering after the heat treatment. Here, 


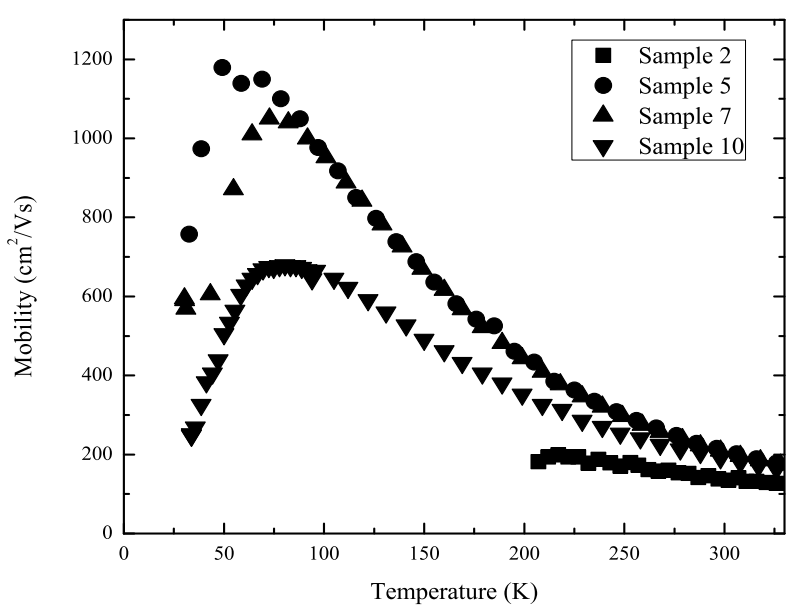

FIG. 5: Carrier concentration from TDH measurements as a function of temperature.

it should be noted that the mobility is higher for the samples treated at 1300 and $1400^{\circ} \mathrm{C}$ (nos. 5 and 7 ) compared to that for the $1500^{\circ} \mathrm{C}$ treated sample (no. 10), possibly indicating that "new" scattering centers are activated in the latter sample.

The concentration of the most pronounced impurities has been determined using SIMS, Fig. 6. The elements $\mathrm{Al}, \mathrm{Si}, \mathrm{Ni}$, and Fe occur with concentrations between $10^{16}$ and $10^{17} \mathrm{~cm}^{-3}$, while $\mathrm{Mg}$ has a concentration of $\sim 5 \times 10^{17} \mathrm{~cm}^{-3}$; within the experimental accuracy the concentration of all these elements remain constant with annealing temperature. The $\mathrm{H}$ concentration is below the detection limit of the SIMS instrument used, that is $\leq 5 \times$ $10^{17} \mathrm{~cm}^{-3}$. For Li, a reduction in the concentration is observed from $\sim 1 \times 10^{17} \mathrm{~cm}^{-3}$ after

growth to $1 \times 10^{15} \mathrm{~cm}^{-3}$ for the samples treated at $1500^{\circ} \mathrm{C}$. As previously pointed out, a build-up of Li in the near surface region is observed, but this region is removed by polishing in order to obtain a uniform impurity concentration throughout the samples. These results are in accordance with previous findings, where heat treatments above $1000^{\circ} \mathrm{C}$ yielded a reduction in the Li concentration with a correlated decrease in the resistivity [21].

\section{DISCUSSION}

\section{A. DLTS and TAS measurements}

The low carrier concentration in the as grown samples as well as the SIMS data suggest that $\mathrm{Li}$ is in sufficient amount to control the electrical conductivity over other electrically 


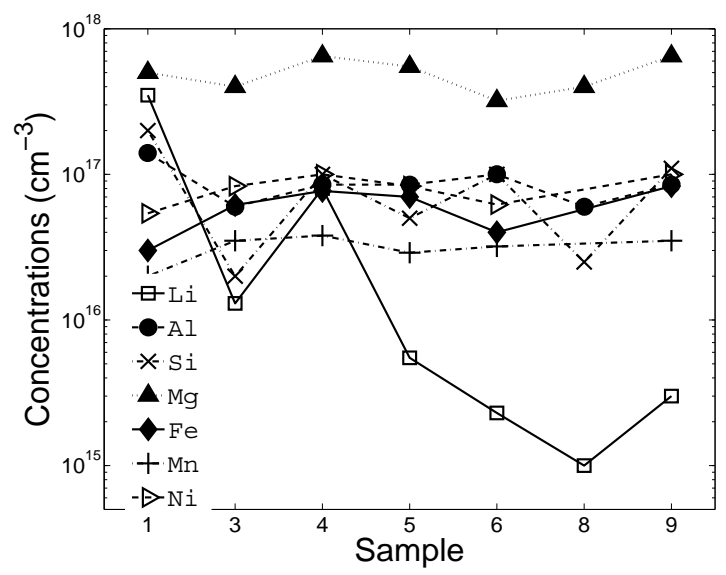

FIG. 6: Measured impurity concentrations in the samples using SIMS.

active intrinsic and impurity related defects. In this case there is a balance between the main acceptor, presumably $L i_{Z n}$, and the donors, where $L i_{I}$ is one of the candidates but several other native or impurity related defects may exist, as discussed in section I. However, the as-grown samples are slightly n-type suggesting that $\sum_{i=1}^{n} N_{D i} \gtrsim N_{A}$, where $N_{D i}$ denotes the concentration of donor $D i$ and $N_{A}$ is the total concentration of acceptors with levels in the lower part of the band gap, resulting in a compensated material with carrier freeze out at a characteristic temperature corresponding to a dominant donor level position around $E_{c}-55 \mathrm{meV}$. After the heat treatments, the Li concentration is reduced and a donor of a different origin becomes dominant, which is manifested by the shift of the freeze-out temperature in the TAS spectra (Fig. 2), where a shallow level around $E_{c}-20 \mathrm{meV}$ is revealed after treatment at and above $1300^{\circ} \mathrm{C}$. The increased electron concentration indicates that the concentration of the dominant compensating center, presumably $L i_{Z n}$, decreases during the heat treatment. Interestingly, the $E_{c}-55 \mathrm{meV}$ is no longer observed in the TAS spectra, suggesting that either i) the $E_{c}-55 \mathrm{meV}$ level originates from $L i_{I}$ or another shallow donor with limited temperature stability, e.g. hydrogen, or ii) $E_{F}$ stays close to $E_{c}$ in the studied temperature interval $(\sim 20$ to $275 \mathrm{~K})$ suppressing detection of the $E_{c}-55 \mathrm{meV}$ level. Indeed, assuming an effective density of states of $5 \times 10^{18} \mathrm{~cm}^{-3}$ in the conduction band of ZnO at RT [24], $E_{F}$ is estimated to be $\sim 20$ and $\sim 90 \mathrm{meV}$ below $E_{c}$ at 20 and $275 \mathrm{~K}$, respectively, and despite the strong correlation between the disappearance of the $E_{c}-55 \mathrm{meV}$ level and the loss of Li, cf Figs. 2 and 6, alternative (ii) is substantiated by the high carrier concentration observed in the CV and TDH measurements. 
The level around $E_{c}-0.3 \mathrm{eV}$ revealed by DLTS, Fig. 3, is commonly labelled E3 in accordance with Ref. [7]. The level appears to be present in all kinds of $\mathrm{ZnO}$ materials [7] [13] [22], irrespective of the growth technique used. E3 has been attributed to oxygen vacancies [10], but impurities like $\mathrm{Fe}$ and $\mathrm{Ni}$, and the second ionization level of $Z n_{I}$ have also been proposed [11] [12]. The amplitude of E3 changes with annealing temperature, as seen in Fig. 3; it increases reaching a maximum at $\sim 1250^{\circ} \mathrm{C}$, before decreasing by about a factor $\sim 4$ between $1250^{\circ} \mathrm{C}$ and $1500^{\circ} \mathrm{C}$ (samples $4-10$ ). Here, it should be mentioned that the rise in amplitude after treatment up to $1250^{\circ} \mathrm{C}$ may partly be due to incomplete filling of the level in the highly resistive (as-grown) sample no. 1 and possibly also to some extent in sample no. 3.

The level E4 is also frequently observed [7] [25], but not in all studies [12] [9]. It has been suggested that E4 is the singly negative charge state of the oxygen vacancy [23], although the identification is rather tentative.

\section{B. Simulation of Hall effect data}

The experimentally observed temperature dependent charge carrier concentration and mobility have been modeled and simulated in order to extract information about the defect levels present, and the procedure follows that of [14]. In the simulations, three donor levels, $E_{D 1}, E_{D 2}$ and $E_{D 3}$, and one compensating (acceptor), $E_{A}$, have been incorporated based on the dominant levels observed in TAS and DLTS (Figs. 2 and 3). The energy positions of $E_{D 1}, E_{D 2}$ and $E_{D 3}$ have been put to $E_{c}-15 \mathrm{meV}, E_{c}-55 \mathrm{meV}, E_{c}-0.34 \mathrm{eV}$, respectively, in the simulations. The position of the first level $\left(E_{D 1}\right)$ is slightly shallower than estimated from TAS, but within the accuracy of the TAS estimate which is rather poor $(\sim 5 m e V)$ because of the low freeze out temperature. The latter level, $E_{D 3}$, is most clearly revealed by $\mathrm{TDH}$ in the strongly compensated (as grown) sample no. 2; modelling of the TDH data for this sample yields an energy position for $E_{D 3}$ of $\sim E_{c}-0.34 \mathrm{eV}$, which is slightly deeper than that obtained by DLTS for the E3 level $\left(\sim E_{c}-0.30 \mathrm{eV}\right)$ in the less compensated (annealed) sample nos. 5,7 and 10. This difference may arise from the fact that overlapping levels with positions around $E_{c}-0.3 \mathrm{eV}$ exist, as has been found by TAS and DLTS previously using as-grown samples [9] [14] and/or that the rate of electron emission deduced by DLTS for the donor-like E3 level is somewhat enhanced by the electric field present during reverse biasing 
TABLE II: Model parameters for the charge carrier concentrations of the dominant donors and compensating acceptor for the best fit between mobility model and experimental results, where the energy positions of $E_{D 1}, E_{D 2}$ and $E_{D 3}$ are $15 \mathrm{meV}, 55 \mathrm{meV}$ and $0.34 \mathrm{eV}$ below $E_{c}$, respectively.

\begin{tabular}{|l|l|l|l|l|l|}
\hline \hline Sample & $\begin{array}{l}\text { Peak Hall mobility } \\
\left(\mathrm{cm}^{2} / \mathrm{Vs}\right)\end{array}$ & $\begin{array}{l}{\left[E_{D 1}\right]} \\
\left(\mathrm{cm}^{-3}\right)\end{array}$ & $\begin{array}{l}{\left[E_{D 2}\right]} \\
\left(\mathrm{cm}^{-3}\right)\end{array}$ & $\begin{array}{l}{\left[E_{D 3}\right]} \\
\left(\mathrm{cm}^{-3}\right)\end{array}$ & $\begin{array}{l}{\left[E_{A}\right]} \\
\left(\mathrm{cm}^{-3}\right)\end{array}$ \\
\hline 2 & 200 & $6.0 \times 10^{16}$ & $6.0 \times 10^{16}$ & $6.0 \times 10^{16}$ & $1.34 \times 10^{17}$ \\
5 & 1180 & $9.6 \times 10^{15}$ & $1.3 \times 10^{17}$ & $6.0 \times 10^{15}$ & $6.0 \times 10^{15}$ \\
7 & 1050 & $1.5 \times 10^{16}$ & $1.0 \times 10^{17}$ & $6.0 \times 10^{15}$ & $1.1 \times 10^{16}$ \\
10 & 680 & $3.8 \times 10^{16}$ & $2.5 \times 10^{17}$ & $6.0 \times 10^{15}$ & $2.0 \times 10^{16}$ \\
\hline \hline
\end{tabular}
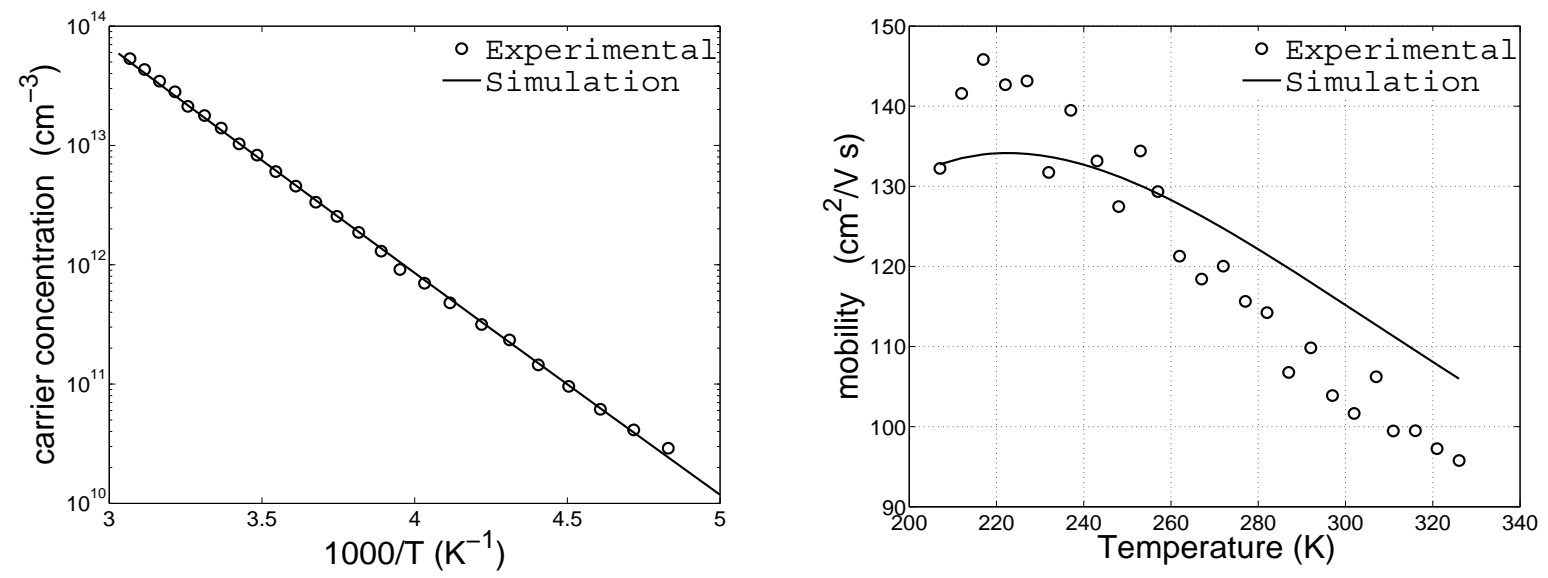

FIG. 7: Experimental and simulated data for sample no. 2; a) the carrier concentration versus the reciprocal absolute temperature and b) the conductivity mobility as a function of temperature

(Poole-Frenkel effect). During the TDH modelling for the heat treated samples (nos. 5,7 and $10)$, the concentration of $E_{D 3},\left[E_{D 3}\right]$, is put equal to that of $E_{c}-0.30 \mathrm{eV}$, as determined by DLTS, while $\left[E_{D 1}\right],\left[E_{D 2}\right]$, and $\left[E_{A}\right]$ have been used as fitting variables (the brackets denote concentration values). The results for the best fits are given in Table II, and Figs. 7 and 8 compare the measured and simulated carrier concentration and mobility values for samples nos. 2 and 7 . Note that the variation of the Hall coefficient with temperature is taken into account and the modelling is optimized with respect to the conductivity mobility.

The sum of the individual donor concentrations given in Table II agrees within $10 \%$ with the charge carrier concentration obtained by CV measurements, Table I. This holds for all 

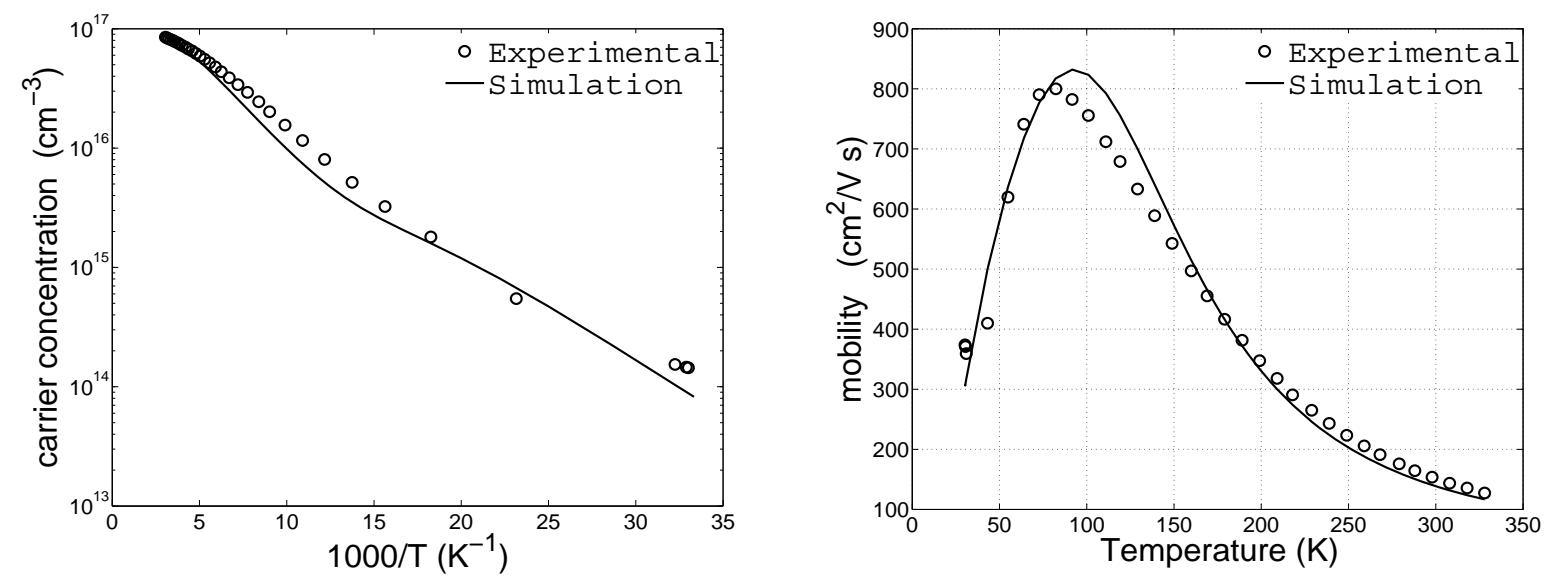

FIG. 8: Experimental and simulated data for sample $7\left(1400^{\circ} C\right)$ for a) the carrier concentration versus the reciprocal absolute temperature and b) the conductivity mobility as a function of temperature

the samples except no. 2 (as grown) which is strongly compensated and where the values given in Table II are less unique compared to those for the other samples; for instance, it is not possible to distinguish between $\left[E_{D 1}\right]$ and $\left[E_{D 2}\right]$ in sample no. 2 although the simulations show with a high degree of confidence that the ratio $\frac{\left[E_{D 1}\right]+\left[E_{D 2}\right]+\left[E_{D 3}\right]}{\left[E_{A}\right]}$ equals $\sim 1.3-1.5$ and that $\left[E_{D 1}\right]+\left[E_{D 2}\right]<\left[E_{A}\right]$.

$\left[E_{D 3}\right]$ in sample no. 2 is about one order of magnitude higher than in the annealed samples, Table II. This trend is fully consistent with the DLTS results for E3 showing a decrease in concentration from $\sim 2 \times 10^{16} \mathrm{~cm}^{-3}$ in sample no. $4\left(1250^{\circ} \mathrm{C}\right)$ to $\lesssim 6 \times 10^{15} \mathrm{~cm}^{-3}$ in samples $5-10\left(\geq 1300^{\circ} \mathrm{C}\right.$ anneals), Fig. 3. Furthermore, previous TDH and TAS studies [14] of as-grown samples of similar kind as used in this work reveal also a high initial concentration of E3 $\left(\sim 1 \times 10^{17} \mathrm{~cm}^{-3}\right)$. Hence, combining all these data from DLTS, TDH, and TAS measurements, it appears that E3 occurs with a concentration of $\sim 1 \times 10^{17} \mathrm{~cm}^{-3}$ in as-grown HT samples, which remains stable for annealing up to $\sim 1200^{\circ} \mathrm{C}$ before a decrease by about one order of magnitude takes place at higher temperatures. This annealing behavior of E3 does not correlate with the temperature dependence of the concentration of any of the major impurities detected by SIMS, Fig. 6, and thus, an assignment of E3 to an impurity is not supported but rather an intrinsic defect.

Interestingly, the $E_{c}-55 \mathrm{meV}$ level is still present and dominant in sample nos. 5,7 and 10, although the level is not observed by TAS, favoring the explanation ii) in section 
IV.A. Moreover, the sum $\left[E_{c}-55 \mathrm{meV}\right]+\left[E_{c}-15 \mathrm{meV}\right]$ is similar in all these three samples, implying that the large increase in mobility is mainly due to a reduction in the amount of compensating centers, which is fully supported by the large decrease in ionized impurity/defect scattering and $\left[E_{A}\right]$ after heat treatment. Further, these results rule out any substantial generation of new electrically active defects due to the high-temperature anneals employed.

\section{Influence of $\mathrm{Li}$ and other residual impurities}

The SIMS data disclose several impurities with concentrations in the $10^{17} \mathrm{~cm}^{-3}$ range (Fig. 6), and one can suspect that the carrier concentration is to a large extent governed by extrinsic defects/impurities. Li is, indeed, one of the main candidates, and it has been proposed that its amphoteric behavior results in self-compensation and an increase in the resistivity [5]. Thus, $L i_{Z n}$ is considered a major contributor to [ $\left.E_{A}\right]$ [21], which is strongly substantiated by the correlation between the present TAS/TDH data (Fig. 2 and Table II) and the SIMS data in Fig. 6. Furthermore, this correlation unambiguously excludes $L i_{I}$ as a main contributor to the donor-like levels $E_{D 1}$ and $E_{D 2}$. The TDH data show that $\left[E_{D 1}\right]$ and $\left[E_{D 2}\right]$ remain above $\sim 1 \times 10^{16}$ and $\sim 1 \times 10^{17} \mathrm{~cm}^{-3}$, respectively, irrespective of the heat treatment used and with an increasing trend as a function of treatment temperature, while concurrently the Li concentration decreases by two orders of magnitude from $\sim(2-$ $3) \times 10^{17}$ to $\sim(2-3) \times 10^{15} \mathrm{~cm}^{-3}$, as revealed by the SIMS data. These conclusions are also corroborated by calculated values of the formation energies of $L i_{Z n}$ and $L i_{I}$ [2]; assuming thermal equilibrium one obtains $\frac{\left[L i_{Z n}\right]}{\left[L i_{I}\right]} \approx \exp \left(\left(E_{F o r m}\left(L i_{Z n}\right)-E_{F o r m}\left(L i_{I}\right)\right) / k T\right)$, where $E_{F o r m}\left(L i_{Z n}\right)$ and $E_{F o r m}\left(L i_{I}\right)$ are the formation energy of $L i_{Z n}$ and $L i_{I}$, respectively.

For a Fermi level position of $E_{g} / 2$, the ratio $\frac{\left[L i_{Z n}\right]}{\left[L i_{I}\right]}$ equals to $8 \times 10^{10}$ at RT $\left(\right.$ and $1.5 \times 10^{2}$ at $\left.1500^{\circ} \mathrm{C}\right)$ applying the theoretical estimates of $E_{F o r m}\left(L i_{Z n}\right)$ and $E_{F o r m}\left(L i_{I}\right)$ given by Wardle et al.[2]. Thus, $L i_{Z n}$ is predicted to prevail strongly over $L i_{I}$ in the studied samples and no contribution of sufficient magnitude from the $L i_{I}$ donor can be detected.

Other important impurities are $\mathrm{Al}$ and $\mathrm{H}$, which both are expected to be donor-like. It has been proposed that the $E_{c}-55 \mathrm{meV}$ level is due to $\mathrm{Al}$ [26] [14], and this proposal is supported by our SIMS and TAS data. The H concentration is below the SIMS detection limit $\left(<5 \times 10^{17} \mathrm{~cm}^{-3}\right)$, but $\mathrm{H}$ is also a likely candidate for either the $E_{c}-55 \mathrm{meV}$ or the 
$E_{c}-15 \mathrm{meV}$ levels. However, $\mathrm{H}$ is known to be mobile at relatively low temperatures [27] [28] [29], and is not likely to exist in a free (isolated) position [8]; according to infrared absorption studies of similar samples as used in the present study the majority of the Hrelated absorption bands disappears after annealing at modest temperatures $\left(\lesssim 600^{\circ} C\right)[30]$. On the other hand, Lavrov et al [27] have reported that the prominent H-related band at $\sim 3577 \mathrm{~cm}^{-1}$ remains stable up to $1200^{\circ} \mathrm{C}$ in hydrothermal samples. However, the $3577 \mathrm{~cm}^{-1}$ is primarily ascribed to a OH-Li complex, which can be regarded as a hydrogen-passivated $L i_{Z n}$ acceptor and not a donor-like defect. Hence, $\mathrm{H}$ is expected to play a minor role for both the $E_{c}-55 \mathrm{meV}$ and $E_{c}-15 \mathrm{meV}$ levels, which exist up to temperatures of $1500^{\circ} \mathrm{C}$.

From the above discussion a consistent scenario can be proposed, where a large fraction of Li resides in the $L i_{Z n}$ configuration acting as a compensating center in as grown samples and samples treated at low temperatures $\left(<1100^{\circ} \mathrm{C}\right)$. A balance between donors and acceptors in the $\sim 10^{17} \mathrm{~cm}^{-3}$ range results in a compensated n-type material exhibiting strong ionized impurity scattering reducing the conductivity mobility. As the Li concentration is reduced by heat treatment at sufficiently high temperatures, both the amount of compensating centers and ionized impurity scattering are reduced, significantly improving the electrical properties of the HT ZnO samples. During these treatments the total concentration of donors remains stable except for a reduction in $[E 3]$.

\section{CONCLUSIONS}

In conclusion, DLTS, TAS, and TDH measurements followed by SIMS studies, have been carried out in order to determine both electronic states in the upper part of the band gap and the concentration of the most prominent residual impurities. The SIMS results unveil that the concentration of the major impurities $\mathrm{Al}, \mathrm{Si}, \mathrm{Mg}, \mathrm{Fe}$ and $\mathrm{Ni}$ do not change after heat treatments up to $1500^{\circ} \mathrm{C}$, while a gradual reduction from $\sim 10^{17}$ to $\sim 10^{15} \mathrm{~cm}^{-3}$ takes place for $\mathrm{Li}$ in the temperature range 1100 to $1500^{\circ} \mathrm{C}$. The results from DLTS and TAS show at least five different levels having energy positions of $E_{c}-20 \mathrm{meV}, E_{c}-55 \mathrm{meV}$, $E_{c}-0.220 \mathrm{eV}, E_{c}-0.30 \mathrm{eV}$, and $E_{c}-0.57 \mathrm{eV}$, where the $E_{c}-55 \mathrm{meV}$ level is the freeze out level for samples treated at temperatures $<1300^{\circ} \mathrm{C}$ while after annealing at higher temperatures freeze out takes place at the $E_{c}-20 \mathrm{meV}$ level. The TDH measurements show a significant increase in the mobility for the heat treated samples, where a peak mobility 
of $1180 \mathrm{~cm}^{2} / \mathrm{Vs}$ is reached for a sample treated at $1300^{\circ} \mathrm{C}$. The results imply strongly that Li in n-type HT ZnO samples occurs almost exclusively in the substitutional (acceptor-like) form $\left(L i_{Z n}\right)$, and theoretical predictions that the formation of $L i_{Z n}$ prevails over $L i_{I}$ for Fermi level positions at and above $E_{g} / 2$ are supported. The identity of the different levels observed is discussed and evidence is obtained for the involvement of $\mathrm{Al}$ in the $E_{c}-55 \mathrm{meV}$ defect while the $E_{c}-0.3 \mathrm{eV}$ level is considered to be of intrinsic origin.

\section{Acknowledgments}

This work was supported by the Norwegian Research Council through the NanoMat program.

[1] C. H. Park, S. B. Zhang, and S. Wei1, Phys. Rev. B 66, 073202 (2002).

[2] M. G. Wardle, J. P. Goss, and P. R. Briddon, Phys. Rev. B 71, 155205 (2005).

[3] O. F. Schirmer, J. Phys. Chem. Solids 29, 1407 (1968).

[4] P. H. Kasai, Phys. Rev. 130, 989 (1963).

[5] C. Jagadish and S. J. Pearton, eds., Zinc Oxide Bulk, Thin films and Nanostructures (Elsevier, Oxford, 2006).

[6] O. F. Schirmer and D. Zwingel, Solid State Commun. 8, 1559 (1970).

[7] F. D. Auret, S. A. Goodman, M. J. Legodi, W. E. Meyer, and D. C. Look, Appl. Phys. Lett. 80, 1340 (2002).

[8] E. V. Monakhov, A. Yu. Kuznetsov, and B. G. Svensson, Journal of Physics D - Applied Physics 42, 153001 (2009).

[9] H. von Wenckstern, H. Schmidt, M. Grundmann, M. W. Allen, P. Miller, R. J. Reeves, and S. M. Durbin, Appl. Phys. Lett. 91, 022913 (2007).

[10] J. C. Simpson and J. F. Cordaro, J. Appl. Phys. 63, 1781 (1988).

[11] Y. Jiang, N. C. Giles, and L. E. Halliburton, j. Appl. Phys. 101, 093706 (2007).

[12] G. Brauer, W. Anwand, W. Skorupa, J. Kuriplach, O. Melikhova, C. Moisson, H. von Wenckstern, H. Schmidt, M. Lorenz, and M. Grundmann, Phys. Rev. B 74, 045208 (2006). 
[13] U. Grossner, S. Gabrielsen, T. M. Børseth, J. Grillenberger, A. Yu. Kuznetsov , and B. G. Svensson, Appl. Phys. Lett. 85, 2259 (2004).

[14] R. Schifano, E. V. Monakhov, L. Vines, B. G. Svensson, W. Mtangi, and F.D. Auret, J. Appl. Phys 106, 043706 (2009).

[15] R. Schifano, E. V. Monakhov, B. G. Svensson, W. Mtangi, P. J. Janse van Rensburg, and F. D. Auret, Physica B 404, 4344 (2009).

[16] O. Lopatiuk, L. Chernyak, A. Osinsky, and J. Q. Xie, Appl. Phys. Lett. 87, 214110 (2005).

[17] K. Kuriyama, M. Ooi, K. Matsumoto, and K. Kushida, Appl. Phys. Lett. 89, 242113 (2006).

[18] Z.-Q. Fang, B. Claflin, D. C. Look, and G. C. Farlow, J. Appl. Phys. 101, 086106 (2007).

[19] T. Maqsood, Master's thesis, University of Oslo (2008).

[20] B.G. Svensson, K.-H. Rydén, and B.M.S. Lewerentz, J. Appl. Phys. 66, 1699 (1989).

[21] B. G. Svensson, T. Moe Børseth, K.M. Johansen, T. Maqsood, R. Schifano, U. Grossner, J.S. Christensen, L. Vines, P. Klason, Q.X. Zhao, et al., Mat. Res. Soc. Symp. Proc. 1035, L04 (2008).

[22] G. H. Kassier, M. Hayes, F. D. Auret, M. Mamor, and K. Bouziane, J. Appl. Phys. 102, 014903 (2007).

[23] T. Frank, G. Pensl, R. Tena-Zaera, J. Zúñiga-Pérez, C. Matńez-Tomás, V. Muñoz-Sanjosé, T. Ohshima, H. Itoh, D. Hofmann, D. Pfisterer, et al., Appl. Phys A 88, 141 (2007).

[24] N. N. Syrbu, I. M. Tiginyanu, V. V. Zalamai, V. V. Ursaki, and E. V. Rusu, Physica B 353, $111(2004)$.

[25] M. Hayes, F. D. Auret, P. J. Janse van Rensburg, J. M. Nel, W. Wesch, and E. Wendler, phys. stat. sol. (b) 244, 1544 (2007).

[26] B. K. Meyer, H. Alves, D. M. Hoffmann, W. Kriegseis, D. Forster, F. Bertram, J. Christen, A. Hoffmann, M. Straburg, and M. Dworzak, Phys. Stat. Sol. (b) 241, 231 (2004).

[27] E. V. Lavrov, F. Borrnert, and J. Weber, Phys. Rev. B 71, 035205 (2005).

[28] E. V. Lavrov, F. Herklotz, and J. Weber, Phys. Rev. B 79, 165210 (2009).

[29] K. M.Johansen, J. S. Christensen, E. V. Monakhov, A. Yu. Kuznetsov, and B. G. Svensson, Appl. Phys. Lett. 93, 152109 (2008).

[30] H. Haug et. al., to be published. 